\title{
ANÁLISIS COYUNTURAL DE LAS ZEDES Y EL BICENTENARIO DE INDEPENDENCIA DE HONDURAS: EL NUEVO MODELO DE COLONIZACIÓN
}

\author{
CONJUNCTURAL ANALYSIS OF THE ZEDES AND THE BICENTENNIAL \\ OF HONDURAS'S INDEPENDENCE: THE NEW COLONIZATION MODEL
}

\author{
Diana Yenifer Servellón Castellanos ${ }^{1}$
}

DOI: https://doi.org/10.5377//rd.v42i1.12932

\section{RESUMEN:}

El presente análisis, aborda elementos de estudio y debate sobre la creación de las Zonas de empleo y desarrollo (ZEDES) en Honduras visto desde una perspectiva territorial y jurídica, comparando el modelo de colonizaje español y la nueva forma de colonizaje de las elites de poder en Honduras en la época contemporánea. En ese sentido se presentan las formas en que se han establecido las violaciones a los derechos de las comunidades históricamente y las prácticas de discriminación y exclusión hacia la población hondureña en el marco de 200 años de independencia nacional en el marco jurídico. Un importante enfoque que devela el sometimiento, las prácticas políticas, la falta de garantías jurídicas, la violentacion de derechos humanos y la perpetuación de la impunidad disfrazada de un modelo económico.

PALABRAS CLAVES: Independencia, ZEDES, Territorio, Leyes.

\section{ABSTRACT}

This analysis addresses elements of study and debate on the creation of Employment and Development Zones (ZEDES) in Honduras seen from a territorial and legal perspective, comparing the Spanish colonization model and the new form of colonization of power elites. in Honduras in contemporary times. In this sense, the ways in which the violations of the rights of the communities have been established historically and the practices of discrimination and exclusion towards the Honduran population in the framework of 200 years of national independence in the legal framework. An important approach that reveals the submission, the political practices, the lack of legal guarantees, the violation of human rights and the perpetuation of impunity disguised as an economic model.

KEYWORDS: Independence, ZEDES, Territory, Laws.

1 Tesista Master en Diseño, Gestión y Dirección de proyectos de Cooperación Internacional de Universidad Europea del Atlántico, Abogada y Licenciada en Historia por la Universidad Nacional Autónoma de Honduras UNAH.

Correo Electrónico: dianaservellon19@gmail.com 


\section{INTRODUCCION}

A partir de este nuevo contexto histórico en Honduras nos encontramos ante un polémico proyecto de ley conocido como Ciudades Modelos o Zonas de Empleo y Desarrollo (ZEDE), para poder analizar un poco el abordaje de este tema he decido aportar un enfoque hacia la soberanía nacional, desde el inicio de la independencia en Honduras remontándonos históricamente hacia el 15 de septiembre de 1821. Es un análisis que compara la situación del proceso de colonización de los españoles, practicas sobre los territorios hasta la creación de una Constitución de la Republica de Honduras con un sistema democrático, que reside en la soberanía y poder del pueblo.

El propósito se enfoca en preguntarnos ¿Si realmente vivimos y debemos celebrar una independencia nacional, a partir de la concesión de estos territorios en Choluteca, Choloma y Roatán para la creación de ZEDES? Además, es presentar las falecias del modelo económico propuesto a partir del art 329 de la Constitución de la Republica y las afectaciones que ha traído a las comunidades que ante la falta de una Consulta previa, libre e informada han realizado actividades para organizarse y defender la soberanía popular. También se presenta la estructura de creación de las ZEDEs, las violaciones a los derechos humanos de los lideres ambientalistas que han defendido el territorio y la violación a los preceptos constitucionales a raíz de la creación de la Ley Orgánica de las Zonas de Empleo y Desarrollo.

Y es importante realizar este análisis en vista de la coyuntura nacional que amerita investigaciones en torno a esta estructura de ciudades modelo que se encuentra en funcionamiento y ha alertado a la población nacional por la falta de información. Por último, se presentan una serie de conclusiones entorno a las practicas históricas y actuales que violentan las garantías constitucionales de la población hondureña.

\section{METODOLOGÍA}

Se realizó con base a la Teoría social reconocida como la ciencia que estudia el desarrollo, la estructura y la función de la sociedad. Con un enfoque de investigación biográfico narrativo que pretende presentar las diversas formas de los datos recopilados, con una técnica de análisis comparativo.

\section{CONSTRUCCIÓN HISTÓRICA DEL BICENTENARIO}

Estamos a vísperas de conmemorar la celebración de los 200 años de independencia centroamericana, popularmente es conocida como el bicentenario de los países centroamericanos. Este proceso consistió en la emancipación política del régimen colonial español, para ello se abordará un análisis del contexto histórico nacional desde la independencia centroamericana desde el punto de vista histórico.

Con la colonización de Punta Caxinas, hoy Punta Castilla o Cabo de Honduras el 14 de agosto de 1502 a partir de la llegada de Cristobal Colón, inicio un proceso de saqueo a la futura conformación del territorio hondureño. Posteriormente en un segundo viaje, enviado por Hernán Cortes a Honduras llega Cristobal de Olid para este momento existe una desavenencia entre Cortes y Diego de Velásquez quien habría sido nombrado gobernador y propuso a Olid repartirse las tierras, fue así como este último fundo la primera ciudad que nombro como El Triunfo 
de la Cruz. Ante tal situación de traición y "Por tal razón Cortes envía a Francisco de las Casas para resolver el asunto, quien resolvió apuñalar a Cristobal de Olid en complicidad con Gil Gonzales Dávila el conquistador de Nicaragua" (Ortez Colindres, 1975, p.24).

Esta situación anterior solo es un breve resumen de las próximas disputas y desavenir de la colonización creando conflictos entre los españoles y los indígenas habitantes en la población hondureña. Y por eso a partir de la Bula ${ }^{2}$ Inter Coetera del papa Alejandro VI de 1943, que repartió los territorios nuevamente descubiertos y por descubrirse entre España y Portugal trazando una línea desde el polo Ártico hasta el Polo Artantico " (Ortez Colindres, 1975, p.28). "La corona española unifico la organización políticoadministrativa de los territorios conquistados en América Central creando la Capitanía General de Guatemala cuyos límites así como el de las provincias eran demarcados por medio de cedulas reales, que fijaban la competencia y jurisdicción de las autoridades civiles, militares y eclesiásticas” (Ortez Colindres, 1975, p.29).

Fue así como Centroamérica fue sometida y conquistada por tres siglos por potencias de ultramar, pero debido a su evolución política administrativa el modelo europeo no encajaba con la realidad social de los próximos países en configuración. Y así en el estado actual de las investigaciones vemos que es imposible formular con caracteres definitivos una teoría general sobre la revolución americana y la dependencia de América. "Pero se establece que son seis las causas fundamentales en la independencia de América:

2 Documento pontificio que trata materias de fe, asuntos administrativos o judiciales, o concede ciertos privilegios y que está autorizado por el Papa mediante un sello que lleva su nombre.

ISSN: 2521-5159 (En Límea) a) Difusión de las teorías enciclopedistas francesas

b) Hegemonía de mando de los españoles peninsulares que dio lugar al odio de los criollos

c) Graves errores de la política seguida por la península y la decadencia de esta en el marco de la política mundial

d) La agitación hábilmente sostenida de en Latinoamérica por Inglaterra y Francia

e) El recio individualismo de la raza hispánica

f) La reacción de los pueblos precolombinos

Sumado a esto, los problemas de índole económico que también influyeron en la independencia de Centroamérica" (Ortez Colindres, 1975, p.52).

Tal había sido el grado de independencia, que el odio de los criollos contra los españoles había llegado al grado de arrojarlos fuera del país. Sin embargo la independencia de América Central fue pacífica en la cual tuvieron además de las causas apuntadas un influjo indirecto los principios establecidos en las Constituciones de Bayona ${ }^{3}$ y Cádiz ${ }^{4}$. Fue así que el 15 de septiembre de 1821 fue proclamada la independencia de la Capitanía General de Guatemala del Gobierno español. Esta acta de independencia fue redactada por José Cecilio de Valle y firmada por los funcionarios que se reunieron a proclamarla (Ortez Colindres, 1975, p.54-55).

3 El Estatuto de Bayona de 1808 fue el primer texto constitucional español, a pesar de que este lugar suele asignarse a la Constitución de Cádiz de 1812. El Estatuto fue una Carta Otorgada, a través de la cual Napoleón trató de institucionalizar un régimen autoritario, pero con un reconocimiento básico de libertades.

4 Establece Soberanía popular, división de poderes y federalismo, fueron los tres principios que se enarbolaron con la promulgación de la Constitución de Cádiz, el 19 de marzo de 1812, corpus legislativo que intentó ser la base de un Estado con un gobierno monárquico-constitucional.

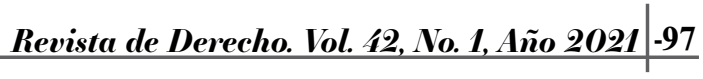


En el caso de Honduras puede considerarse el 28 de septiembre de 1821 como la fecha oficial de independencia este proceso se efectuó en la ciudad de Comayagua y en la Villa de Tegucigalpa de Heredia, como consecuencia de haberse recibido la transcripción del acta levantada en la ciudad de Guatemala el 15 de septiembre del mismo año y un manifiesto suscrito por el Gobernante Político de Centro América, Brigadier Gabino Gainza, en el cual comunicaba los sucesos acaecidos en la capital de la Capitanía General (Cáceres Lara, 1978, p. XI).

Diferentes actitudes se vivieron respecto a la independencia en Comayagua y Tegucigalpa. Mientras en la capital de la gobernación de Honduras se resolvió jurar la independencia sin sujeción alguna a Guatemala y con la precisa condición de que habría únicamente sujeta al gobierno supremo que se estableciera, en la Alcaldía Mayor de Tegucigalpa se acordó proclamar la independencia, contribuir con ella a por cuantos medios estuvieran al alcance hasta sacrificar vidas y haciendas, conservar orden público y unir sus votos con los del pueblo y autoridades de Guatemala (Cáceres Lara, 1978, p. XI).

Esto contrajo diversas controversias entre Tegucigalpa y Comayagua, llegado a este punto Guatemala envió una fuerza de auxilio a Tegucigalpa y Comayagua movilizo sus milicias, pero la cordura de los dirigentes de ambos lugares evito la efusión de sangre que se consideraba segura (Cáceres Lara, 1978, p. XII).

Para la reunión del Congreso o Asamblea Constituyente se pensó que la reunión fuera en Leapaterique o Aguanqueterique; pero por ultimo una comisión preparatoria reunida en Comayagua convino la instalación de la Asamblea se efectuará en el mineral de Cedros, suceso que ocurrió el 29 de agosto de 1824 estando presentes los jefes políticos de Comayagua y Tegucigalpa, el 30 de agosto el Congreso Constituyente emitió decreto disponiendo que el Congreso residiera alternativamente una año en la ciudad de Tegucigalpa y otro en el de Comayagüela (Cáceres Lara, 1978, p. XIII).

El Congreso Constituyente instalado en Tegucigalpa, reanudo sesiones el 16 de septiembre de 1824 fecha en que hizo el escrutinio de votos para Jefe y Vice jefe del Estado de Honduras y no habiendo arrojado la votación mayoría absoluta a favor de ningún candidato, la Asamblea nombro a los ciudadanos Dionisio de Herrera y José Justo Milla en los cargos mencionados. De esta forma quedo constituida la autoridad suprema del Estado que de conformidad con la Constitución del 22 de noviembre de 1824 entro a formar parte de la denominada República Federal de Centro América (Cáceres Lara, 1978, p. XIII-XIV).

La asamblea constituyente siguió trabajando arduamente; dividió al país en siete departamentos que eran, Tegucigalpa, Choluteca, Olancho, Comayagua, Gracias, Santa Bárbara y Yoro. El 3 de octubre de 1825 decreto el primer escudo de armas y el 11 de diciembre del mismo año decreto la primera Constitución Política, quedando así establecida legalmente el Estado de Honduras como miembro de la República Federal de Centroamérica fundada asimismo por la Constitución federal de 22 de noviembre de 1824 , emitida por la Asamblea Nacional Constituyente de Centroamérica (Cáceres Lara, 1978, p.4). Actualmente existen controvertidos debates de expertos jurídicos, quienes informan que han existido 14 Constituciones y otros dicen que ha 
habido 16 de las cuales 13 son nacionales y 3 federativas (Presencia Universitaria, 2019), en ese sentido nuestra última Carta Magna es la de 1982.

En este proceso de independencia, es muy importante conocer la conformación territorial que según describe el historiador Mario Felipe Martínez, el número de vecinos de las poblaciones más grandes de Honduras en ciudades en este periodo de independencia fue el siguiente: Comayagua: 18,383 vecinos; Tegucigalpa: 6,547 vecinos; Choluteca: 5,212 vecinos; Gracias a Dios: 4,776 vecinos; Truxillo: 4, 320 vecinos (Martínez, 2011, p. 231). Por otra parte, en la actualidad vemos que la población de Honduras, creció exponencialmente y según datos del Instituto Nacional de Estadísticas, convivimos en el territorio hondureño 9, 464, 407 habitantes de los cuales se desagregan según género son 4, 605, 894 hombres y 4, 858, 512 mujeres (INE, 2021).

\section{Las Zonas De Empleo Y Desarrollo (ZEDE)}

Las Zonas de Empleo y Desarrollo Económico (ZEDES) conocidas popularmente como "ciudades modelo", tuvieron su antecedente de discusión y aprobación en el Congreso Nacional durante el gobierno de Porfirio Lobo Sosa y la propuesta del economista estadounidense Paul Romer (2006-2010), donde se impusieron reformas constitucionales para la creación de la Ley de Regiones Especiales para el Desarrollo (RED). Para entender lo que conforma esta figura a continuación se comparte la definición realizada por Romer:

Una Charter City va más allá de una zona económica especial (special economic zone, en inglés), ya que esta aumenta su tamaño a la escala de una ciudad y amplia el alcance de sus reformas.
Sus reformas deben extenderse a todas las reglas necesarias para estructurar las interacciones en una ciudad bien administrada y para apoyar el intercambio en una economía de mercado moderna. Las reglas en este contexto abarcan lo que los académicos a menudo denominan "instituciones": las normas sociales y las leyes formales (junto con los sistemas de cumplimiento) que determinan cómo interactúan las personas. Las reglas obsoletas a menudo frenan a las personas. Algunas reglas pueden hacer que sea demasiado fácil ser un criminal o demasiado difícil iniciar un negocio del sector formal. Otras reglas limitan la competencia, por ejemplo, al prohibir que las empresas privadas produzcan y vendan energía eléctrica. Como resultado, los ciudadanos de los países pobres a menudo terminan pagando más por bienes básicos como la electricidad, si es que tienen acceso a ellos (Herrera, 2019).

Esta iniciativa posteriormente fue declarada inconstitucional pues violentaba la soberanía y la forma de gobierno establecida en la Constitución de la Republica de Honduras.

En un segundo momento, la iniciativa fue presentada ante el Congreso Nacional como "Ley de Zonas de Empleo y Desarrollo" mediante decreto 120-2013 la cual fue aprobada y favorecida por la reforma de artículos constitucionales. A partir de esta ley se han propuesto en este proyecto 4 ejes que definen el funcionamiento de las ZEDES que según el consejo de ministros tienen las siguientes características:

1.- Autonomía Jurídica: Gozan de autonomía funcional y administrativa que deben incluir las funciones, facultades y obligaciones que la Constitución y las leyes le confieren a los municipios. 
2.- Jurisdicciones especiales: Tienen tribunales internos que son parte del Poder Judicial, pero funcionan de manera autónoma e independiente y bajo el derecho anglosajón (common law).

3.- Avance tecnológico: En las ZEDE se pueden crear centros financieros, logísticos o comerciales internacionales, ciudades autónomas, zonas económicas especiales, distritos especiales de inversión, distritos energéticos renovables, así como territorios agroindustriales, turísticos, mineros $\mathrm{y}$ forestales, entre otros.

4.- Protección del inversionista: Tienen personalidad jurídica. Están sujetas a un régimen fiscal especial. Pueden contraer obligaciones en tanto no requieran para ello la garantía o el aval solidario del Estado. Pueden celebrar contratos hasta el cumplimiento de sus objetivos en el tiempo y durante varios gobiernos.

En ese análisis de contexto sobre los ejes establecidos para la creación de las ZEDES vemos como centros de pensamiento como el CESPAD, realizan estudios sobre este proyecto e interpretan: "Le dieron personalidad jurídica y un territorio, como sujeto, a las ZEDES. Le dieron un órgano que tiene el carácter legislativo y que se llama Comité de las Mejores Prácticas. Tienen un órgano que hará las veces de Poder Ejecutivo, a través de la figura del Secretario de las ZEDEs. Tienen un Tribunal de Protección de Derechos Individuales, que hará las veces de la Corte Suprema de Justicia. Prácticamente es una forma de Gobierno y se estructura en las ZEDES, lo que implica una renuncia del pueblo de Honduras, de su derecho de ejercer el Poder del Soberano sobre estos territorios. Según la ley, los ciudadanos que radiquen en estas zonas pagarán $16 \%$ como impuesto sobre la renta, mientras el resto del país seguirá pagando un $25 \%$. (CESPAD, 2021).

Las élites se ven en la necesidad de reacomodarse para salir a flote, reorientar y asegurar sus procesos de acumulación capitalista. Las élites se lanzan en la conquista/colonización de nuevos territorios, expanden su capacidad de inversión en las diversas áreas de la economía y, con el aval de los Estados, crean/reforman el marco normativo existente para facilitar la inversión extranjera. Más allá del tema de empleo, en el contexto del proceso electoral lo que entra en juego es la reconfiguración de las élites políticas y la renovación del actual modelo de concentración de la riqueza y despojo territorial, en la cual las zonas de desarrollo prometen ser el proyecto que articulará las apuestas de la élite. (CESPAD, 2021).

La colaboración entre Honduras y Romer fracasó en 2012, cuando el economista se retiró del proceso por falta de transparencia por parte del gobierno y la Corte Suprema de Honduras declaró inconstitucional el concepto de las ciudades modelo. Según su dictamen, el concepto de las ZEDE violaba preceptos constitucionales relacionados con la soberanía, el territorio y la forma de gobierno. Una reestructuración personal de la Corte Suprema y una reforma Constitucional, lideradas por el entonces presidente del Congreso y actual presidente de Honduras, Juan Orlando Hernández, permitieron aprobar en 2013 la Ley Orgánica de las ZEDE (Deutsche Welle 2021).

\section{AFECTACIONES A LOS TERRITORIOS Y JURÍDICOS}




\section{A) Análisis de la situación territorial en Honduras y la instalación de las ZEDES}

La Oficina del Alto Comisionado de las Naciones Unidas para los Derechos Humanos (OACNUDH) define, en su acepción más amplia, que una persona defensora de derechos humanos es aquella que, de forma individual o colectiva, dedica su esfuerzo a promover o defender derechos (OACNUDH 2021).

Pueden resaltarse algunas organizaciones y defensoras y defensores emblemáticos que luchan por su territorio. En el norte del país, se encuentran la Organización Fraternal Negra de Honduras (OFRANEH), con Miriam Miranda en su coordinación; la Fundación San Alonso Rodríguez, con Juana y Juan López; el Movimiento Amplio por la Dignidad y la Justicia (MADJ), con Víctor y Martin Fernández; el Equipo de Reflexión, Investigación y Comunicación de los jesuitas (ERIC-SJ) y Radio Progreso, con el padre Ismael Moreno ("Melo"), Joaquín Mejía y Karla Rivas. En el sur, se pueden mencionar a la Asociación para el Desarrollo de la Península de Zacate Grande (ADEPZA), con su líder histórico, Pedro Canales; el Movimiento Ambientalista Social del Sur por la Vida (MASSVIDA), con German; y el Consejo Indígena Lenca de Reitoca, Francisco Morazán (CILRFM), con Orlando Rodas. En el occidente, se encuentran el Consejo Cívico de Organizaciones Populares e Indígenas de Honduras (COPINH), con Bertita Zúñiga Cáceres; el Movimiento Ambientalista de Santa Bárbara (MAS), con Betty Vásquez en la coordinación; y el Movimiento Indígena Lenca de La Paz (MILPA). Finalmente, en el oriente, se puede destacar al Movimiento Ambientalista de Olancho(International Land Coalition, 2020, p.5).

ISSN: 2521-5159 (En Línea)
Intereses detrás de los ataques en relación con la tierra y los territorios rurales El acaparamiento de tierras, promovido desde la Colonia y renovado cuando se implementó la Ley de Modernización Agrícola en los años noventa, ha favorecido a los grupos de élite del país. Miles de hectáreas de cultivos de palma africana en plena producción, en la zona del Bajo Aguán (norte de Honduras), terminaron en las manos de tres grandes terratenientes. Esta élite fue diversificando su proceso de acumulación y respondiendo. a tendencias regionales y al estímulo de políticas implementadas por los sucesivos gobiernos neoliberales, de forma que se embarcaron en un enorme proyecto de acaparamiento de tierras y de recursos naturales. Algunos llaman a esto el modelo neoliberal capitalista en su fase de restauración extractivista, que consiste en el acaparamiento voraz de los bienes naturales, especialmente el agua, la tierra, la biodiversidad, las playas, los minerales, entre otros. Este proceso se vio facilitado por un marco legal que incluyó una reforma institucional y el respaldo administrativo, legal y coercitivo del Estado (International Land Coalition, 2020, p.9).

El extractivismo en cifras: un país entregado a las concesiones Como en el mejor de los tiempos de la reforma liberal en Honduras, sus últimos gobernantes han optado por implementar una nueva variante del modelo de desarrollo económico capitalista que convierte los recursos y bienes públicos en mercancías: el extractivismo. Al igual que Marco Aurelio Soto y Ramón RosaQ visualizaron que, para atraer el capital extranjero, debían otorgar el territorio en atractivas concesiones, los nuevos reformadores han otorgado el territorio a diversas empresas de capital transnacional y consorcios locales, cuyo capital pertenece a nuevos grupos de poder que, poco a poco, han ido consolidándose a lo largo de la última década. En la actualidad, las concesiones

Revista de Derecho. Vol. 12, No. 1, Año 2021 -101 
mineras se extienden sobre 156 municipios y las concesiones de generación de energía eléctrica8 están en 100 de los 298 municipios; es decir, el $65 \%$ de los municipios (194) cuenta con medios de concesión minera o de proyectos de generación de energía eléctrica. En la mayoría de los casos, las comunidades desconocen que en sus territorios ya existen concesiones, puesto que estas no han iniciado operaciones y se encuentran en fase de exploración o simplemente se encuentran en reserva. Es importante destacar que, mientras una concesión no ha iniciado operaciones, ningún ciudadano ni organismo o institución puede conocer la ubicación de dicha concesión, ya que se encuentra celosamente oculta bajo la conflictiva Ley de Secretos (International Land Coalition, 2020, p.9).

En la insensible carrera por explotar los recursos naturales bajo cualquier costo, el Estado ha irrespetado sus propias leyes, puesto que, hasta julio del 2018, 47 de las concesiones mineras y 25 proyectos de generación de energía estaban dentro de áreas protegidas. El Estado registró 540 concesiones mineras y 307 proyectos de generación de energía, 32 concesiones mineras y 10 proyectos hidroeléctricos dentro de microcuencas declaradas. (International Land Coalition, 2020, p.10).

A partir de este análisis de contexto de la situación de los defensores de medio ambiente $\mathrm{y}$ las concesiones extractivitas realizadas por el Estado de Honduras. Nace la convocatoria y movilización para defender la soberanía del Estado de Honduras de las ZEDES y se ha convertido en el llamado para diversos grupos articulados desde movimientos sociales, organizaciones no gubernamentales y sociedad civil en general, a partir de frenar la concesión de territorios de forma arbitraria y revestida de legalidad afectando a las comunidades, su identidad y medios de subsistencia, ya que tampoco ha existido una consulta previa, libre e informada.

Estás ultimas han realizado también diversas acciones, algunas de las principales consisten en convocatorias desde las bases comunitarias para realizar cabildos abiertos y declarar a los territorios libres de extractivismos y libres de ZEDES. Por otra parte, se han presentado los diversos académicos a presentar sus posiciones en contra de las ZEDES desde los espacios públicos a través de foros con las comunidades, los medios de comunicación y otro grupo presentando acciones legales ante la Corte Suprema de Justicia.

Es importante rescatar algunos elementos que analizan la actual lucha ciudadana contra las ZEDEs, la que ha encontrado simpatía en distintos sectores de la sociedad hondureña. En ese sentido, es de interés analizar cuatros aspectos importantes: i) la identidad colectiva en la lucha contra las ZEDEs, ii) los principales actores en lucha-resistencia y sus discursos programáticos, iii) las principales demandas ciudadanas en la lucha contra las ZEDEs y, iv) la respuesta desde la administración de Hernández y la élite económica a la lucha ciudadana contra las ZEDEs (CESPAD 2021).

Con base en los distintos posicionamientos publicados en el transcurso de la jornada, se identifican las siguientes demandas (CESPAD 2021)::

1. Derogación de la Ley ZEDE.

2. Juicio político contra los diputados y diputadas que reformaron la Constitución de la Republica para aprobar la Ley ZEDEs.

3. Respeto a la autonomía municipal en relación con las declaraciones libres de ZEDEs. 
4. Respeto a la consulta comunitaria y al convenido 169 de la Organización Internacional del Trabajo (OIT).

5. Implementación de políticas de desarrollo sustentable bajo un enfoque de derechos y de género.

6. Retiro de los inversionistas y empresas que están construyendo ZEDEs en el país.

7. Reconocer el papel y vinculación de las organizaciones socioterritoriales en la construcción de programas de desarrollo territorial que respondan a las necesidades y demandas de las poblaciones vulnerables y,

8. Rechazo a toda forma de desarrollo económico que priorice la promoción de los extractivismos (en sus distintas modalidades), la pérdida de la soberanía nacional y el desarrollo de economía de enclaves que refuerzan el despojo, el neocolonialismo, el racismo, la violencia y el patriarcado.
A partir de ellos se ha buscado criminalizar a los líderes comunitarios, por medio de los delitos de usurpación, daños y perjuicios, además de amenazas, debido a la falta de interés de titulación de tierras de las instituciones como el INA.

Una investigación de la ONG Global Witness descubre que en Honduras se vive uno de los niveles más altos de violencia contra los activistas ambientales: más de 120 muertes desde 2010. Una de las causas principales es Los investigadores dicen que la culpa es principalmente de la corrupción del gobierno que rodea a los proyectos de desarrollo como presas, minas y plantaciones de aceite de palma (Mongabay 2017), es decir Honduras se considera el país más peligroso para el activismo ambiental.

El siguiente cuadro muestra las zonas de las ZEDES que desde el 2020 empezaron a funcionar en el país.

\begin{tabular}{|l|l|l|l|l|}
\hline No $^{\circ}$ & $\begin{array}{c}\text { Nombre de las } \\
\text { ZEDEs }\end{array}$ & \multicolumn{1}{|c|}{ Tipo de industria } & \multicolumn{1}{|c|}{ Capital } & \multicolumn{1}{c|}{ Lugar } \\
\hline 1. & $\underline{\text { ZEDE Orquídea }}$ & Agroindustrial & $\begin{array}{l}\text { Grupo empresarial } \\
\text { agroindustrial exportador } \\
\text { de Choluteca. }\end{array}$ & $\begin{array}{l}\text { San Marcos de Colón, } \\
\text { Choluteca. }\end{array}$ \\
\hline $\mathbf{2 .}$ & $\underline{\text { Ciudad Morazán }}$ & $\begin{array}{l}\text { Espacio industrial } \\
\text { para fábricas, casas } \\
\text { y apartamentos }\end{array}$ & $\begin{array}{l}\text { Centroamerican Capital } \\
\text { \& Consulting, yc. }\end{array}$ & Choloma, Cortés. \\
\hline $\mathbf{3 .}$ & $\underline{\text { PRÓSPERA }}$ & $\begin{array}{l}\text { Minería, } \\
\text { educación, } \\
\text { salud, finanzas, } \\
\text { seguro, alimentos, } \\
\text { subsuelo, } \\
\text { agricultura, } \\
\text { finanzas, } \\
\text { manufactura y } \\
\text { construcción. }\end{array}$ & $\begin{array}{l}\text { Honduras Prospera, } \\
\text { países). }\end{array}$ & $\begin{array}{l}\text { Roatán, Islas de la } \\
\text { Bahía. Con posibilidad } \\
\text { de expandirse hacia } \\
\text { Amapala, Cortés, Puerto } \\
\text { Castilla, Cuyamel, La } \\
\text { Ceiba y San Pedro Sula. }\end{array}$ \\
\hline
\end{tabular}

- Fuente: Elaboración Bladimir López, analista del CESPAD 
Es importante mencionar que también existe una ZEDE nombrada Startup City MARIPOSA, promueve la idea de un "santuario de salud», accesible para la población local es un hospital de 14.000 metros cuadrados», que realizaría intervenciones asequibles a los lugareños. Asimismo, incluyen el concepto de un «hotel de maternidad» que busca atraer el «turismo de maternidad». pueden ingresar al siguiente enlace que hace alusión a su promoción https:// mariposa.hn/en/resources/zede-in-honduras/ promociona la visualización de su ZEDE en algún lugar cercano al mar Caribe, con «playas limpias», «rodeada por granjas orgánicas», que se convertirá «en un santuario de salud con clínicas que utilizan una combinación de enfoques médicos holísticos, naturopáticos, funcionales e integradores (Criterio Hn 2021).

A continuación, también se presenta el mapa del territorio hondureño propuesto para la instalación de las ZEDES:

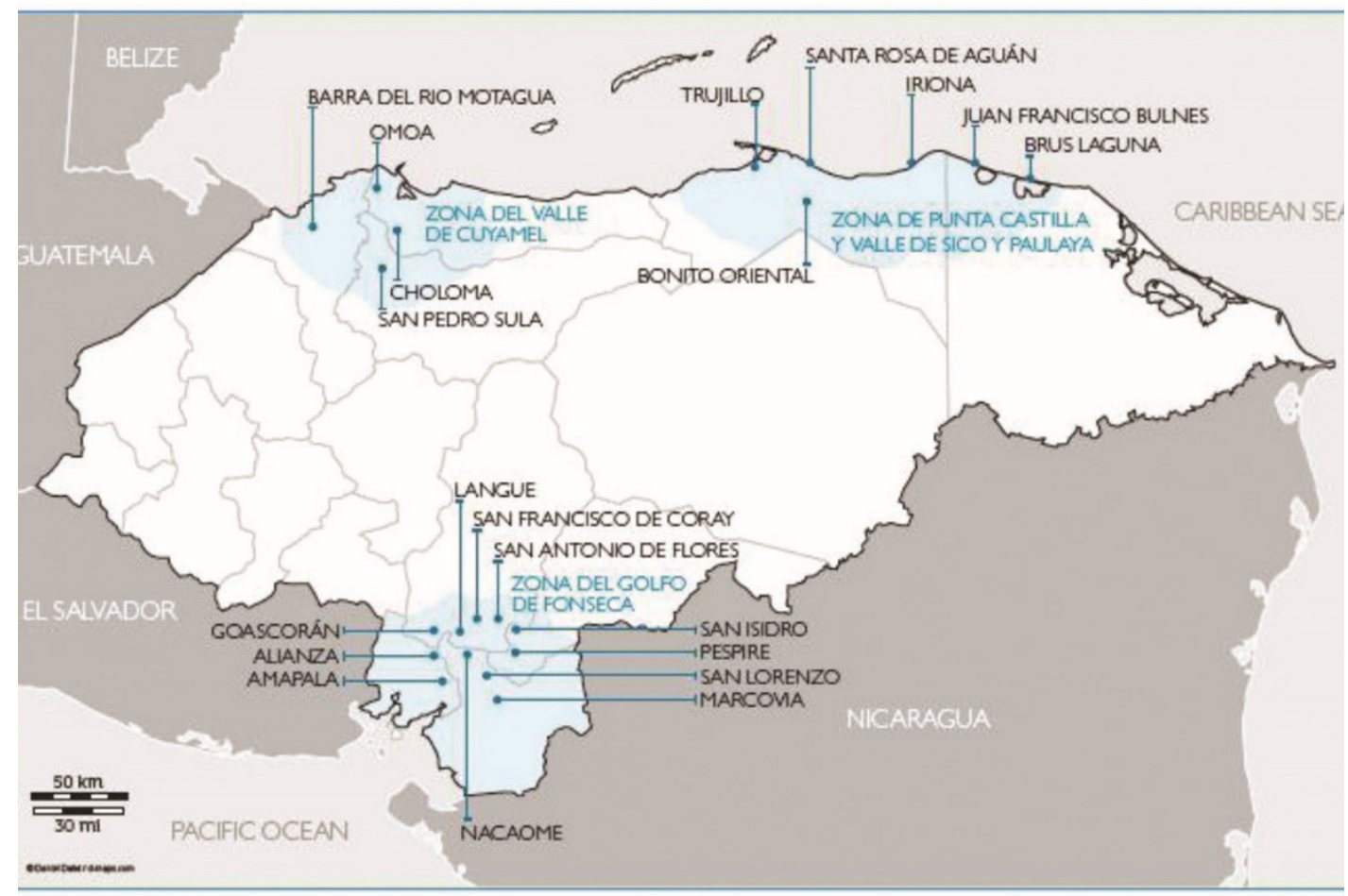

Fuente: El regreso de los enclaves a Honduras en el siglo XXI

B) Análisis de la situación jurídica de las ZEDES Un ejemplo práctico que conocemos de las ZEDES es el caso de ZEDE PROSPERA en la Isla de la Bahía. La ciudad modelo espera tener para 2025, 10,000 habitantes y una inversión extranjera de $\$ 500,000$ millones de dólares y para lograr este objetivo de registrar 2,500 residentes por año, aproximadamente 208 personas cada mes (La Prensa, 2021). 
A partir de su creación se ha solicitado a los interesados inscribirse en la siguiente dirección: https://portal.eprospera.hn./ para solicitar una residencia de la cual deben de pagar los hondureños \$260 dólares y extranjeros \$1,300 dólares por medio de un contrato de residencia

Por otra parte, Prospera Arbitration center (PAC) es el centro de arbitraje designado para conocer las causas legales en: asuntos comerciales, agravios, desalojos, sanción civil-causa criminal, actividad peligrosa. (La Prensa 2021)

En su tesis de doctorado de la Universidad de Bremen, en Alemania, Nuila Hermannsdorfer investiga las implicaciones legales de las ZEDE en el futuro del derecho internacional público. Según la abogada, una de las principales cuestiones es "cómo se aplicarán los Derechos Humanos o el Derecho Internacional Laboral en una jurisdicción no estatal." La ZEDE "Roatán Próspera" tiene su propio tribunal de arbitraje, que se hará cargo de la mayoría de las disputas. Aplicará el Código de Derecho Común de Próspera, que, según afirma Nuila
Hermannsdorfer, "es un compendio de normas de derecho común, que se ha creado importando las leyes más favorables para la protección de la propiedad y de las transacciones financieras de jurisdicciones de diferentes países, incluyendo de leyes y regulaciones del derecho estatal de los Estados Unidos.” Esto entorpece el acceso a la Justicia, dice Nuila Hermannsdorfer: "Una de las grandes interrogantes es cómo un abogado puede representar a las comunidades afectadas navegando entre diferentes jurisdicciones. (Deutsche Welle 2021).

El fundamento jurídico de creación de la ley orgánica de las ZEDES se encuentra en el artículo 329 de la Constitución de la Republica de Honduras que hace referencia al desarrollo económico y la colaboración de todos los poderes del Estado de Honduras.

Pero realizando un análisis de la ley orgánica de las ZEDES, vemos que desde su constitución se violentan los siguientes preceptos constitucionales;

\begin{tabular}{|c|c|c|}
\hline Contenido & $\begin{array}{l}\text { Leyes hondureñas } \\
\text { violentadas }\end{array}$ & Ley Orgánica de las ZEDES \\
\hline Marco legal & $\begin{array}{l}\text { Constitución de la } \\
\text { Republica de Honduras, } \\
\text { art. } 2 \text { (soberanía del } \\
\text { pueblo), art } 303 \text { al } 306 \\
\text { (Poder judicial) }\end{array}$ & $\begin{array}{l}\text { Articulo 8.- La jerarquía normativa aplicable en las } \\
\text { Zonas de Empleo y Desarrollo Económico (ZEDE) } \\
\text { será la siguiente: } \\
\text { 1) La Constitución de la República en lo que sea } \\
\text { aplicable; } \\
\text { 2) Los Tratados Internacionales celebrados por el } \\
\text { Estado de Honduras en lo que sean aplicables; } \\
\text { 3) La presente Ley Orgánica de las Zonas de Empleo } \\
\text { y Desarrollo Económico (ZEDE); } \\
\text { 4) Las leyes señaladas en las Disposiciones Finales de } \\
\text { la presente Ley Orgánica; y, } \\
\text { 5) La normativa interna emanada de las autoridades } \\
\text { de las Zonas de Empleo y Desarrollo Económico } \\
\text { (ZEDE) o incorporada por las mismas. }\end{array}$ \\
\hline
\end{tabular}




\begin{tabular}{|c|c|c|}
\hline Contenido & $\begin{array}{l}\text { Leyes hondureñas } \\
\text { violentadas }\end{array}$ & Ley Orgánica de las ZEDES \\
\hline $\begin{array}{l}\text { Jurisdicciones } \\
\text { especiales }\end{array}$ & $\begin{array}{l}\text { Constitución de la } \\
\text { Republica de Honduras, } \\
\text { art } 303 \text { (Poder judicial) }\end{array}$ & $\begin{array}{l}\text { Artículo 14.-Las Zonas de Empleo y Desarrollo } \\
\text { Económico (ZEDE) están sujetas a una jurisdicción } \\
\text { especial y contarán con tribunales autónomos e } \\
\text { independientes con competencia exclusiva en todas } \\
\text { las instancias sobre las materias que no estén sujetas a } \\
\text { arbitraje obligatorio. Los mismos serán creados por el } \\
\text { Poder Judicial por medio del Consejo de la Judicatura } \\
\text { a propuesta del Comité de Adopción de Mejores } \\
\text { Prácticas y operarán bajo la tradición de derecho común } \\
\text { o anglosajón (common law), u otras de conformidad al } \\
\text { Artículo } 329 \text { de la Constitución de la República }\end{array}$ \\
\hline $\begin{array}{l}\text { Sometimiento a } \\
\text { arbitraje }\end{array}$ & $\begin{array}{l}\text { Constitución de la } \\
\text { Republica de Honduras, } \\
\text { art } 313 \text { (Poder judicial) }\end{array}$ & $\begin{array}{l}\text { Art. 20. Arbitraje obligatorio para todos los asuntos de } \\
\text { carácter contractual o patrimonial. }\end{array}$ \\
\hline $\begin{array}{l}\text { Administración } \\
\text { del régimen } \\
\text { fiscal }\end{array}$ & $\begin{array}{l}\text { Constitución de la } \\
\text { Republica de Honduras, } \\
\text { art } 342 \text { al } 343 \text { (Tratados } \\
\text { Internacionales) } \\
\text { Código Tributario }\end{array}$ & $\begin{array}{l}\text { ARTICUL O 32.-Las Zonas de Empleo y Desarrollo } \\
\text { Económico (ZEDE) son zonas fiscales y aduaneras } \\
\text { extraterritoriales, distintas á las del resto del territorio } \\
\text { nacional. } \\
\text { Las personas naturales y jurídicas que operen dentro } \\
\text { de las Zonas de Empleo y Desarrollo Económico } \\
\text { (ZEDE) recibirán trato en base al principio de Nación } \\
\text { Más Favorecida (NMF), para lo cual obtendrán la } \\
\text { extensión automática de cualquier mejor tratamiento } \\
\text { que se conceda o se haya concedido a las demás partes } \\
\text { en un acuerdo de comercio internacional suscrito por } \\
\text { el Estado de Honduras. }\end{array}$ \\
\hline $\begin{array}{l}\text { Declaración de } \\
\text { baja densidad } \\
\text { poblacional }\end{array}$ & $\begin{array}{l}\text { Ley de Municipalidades } \\
\text { Artículo } \mathrm{N}^{\circ} 12 \text { de la }\end{array}$ & Articulo 38 y 39: Ámbito territorial \\
\hline $\begin{array}{l}\text { Derecho de } \\
\text { los pueblos } \\
\text { indígenas }\end{array}$ & $\begin{array}{l}\text { Constitución de la } \\
\text { Republica de Honduras, } \\
\text { art } 105 \text { al } 107 \text { (El } \\
\text { derecho de propiedad } \\
\text { privada) }\end{array}$ & $\begin{array}{l}\text { Articulo } 43 \text { Los derechos de propiedad de los pueblos } \\
\text { indígenas }\end{array}$ \\
\hline
\end{tabular}




\section{CONCLUSIONES}

- Es importante reconocer que las concesiones del territorio es una práctica realizada desde la colonización, donde la clase privilegiada se adueñaba de una porción de tierra y esta era explotada para su propio beneficio. Después de la independencia de la Colonia española se inició en Centroamérica, y particularmente en Honduras, con un proceso de acaparamiento de la tierra por parte de sectores criollos poderosos. Vemos que en la actualidad con las ZEDES se está realizando el mismo proceso de distribución de tierra entre socios políticos y de las elites más fuertes del país, bajo mecanismos de terror, amenaza hacia los defensores y líderes comunitarios.

- En el proceso de defensa de soberanía territorial es importante capacitar a los líderes comunitarios entorno a los procesos de la ley de municipalidades y asesoramiento jurídico entorno al proceso de titulación de tierras.

- Las ZEDES no representan un modelo de generación de empleo ya que no se ha presentado ningún mecanismo de su esquema laboral, seguro social o de otra índole, por otra parte, lo que conocemos es que debemos de pagar para poder ingresar a estas zonas exclusivas.

- La ley orgánica de las ZEDES no contempla la consulta libre, previa e informada, esto se debe a que el modelo inicial era realizarlas en zonas donde existiera baja densidad poblacional, pero estas en la realidad se ubican en zonas de protección ambiental.
- En la realidad las ZEDES apuntan a un modelo neoliberal, como lo establece el art 2 de su Ley, son creadas con el objetivo de desarrollar centros financieros e internacionales, distritos especiales de inversión, distritos energéticos renovables, zonas mineras sociales, zonas forestales sociales entre otras, impulsando la privatización, el liberalismo del mercado y la concesión extractivista.

- A partir de su configuración las ZEDES crean un modelo que divide a la población en 2 sectores creando un instrumento para un sector privilegiado desconociéndose el estatus que tendrían las personas que habiten las ZEDES. Quedando al desconocimiento publico el tipo de marco fiscal que se va emplear y las formas en que se puede evitar la fuga de capitales y el lavado de activos y no convertirse en paraísos fiscales, especialmente para el control de las posibles zonas de refugio de corruptos y narcotraficantes.

- Las organizaciones de la sociedad civil indicaron que no existe legislación o reglamentación que hagan efectivos los derechos reconocidos en el Convenio 169 de la Organización Internacional del Trabajo, ratificado por el Estado desde 1994, siendo así que las ZEDES ponen en tela de juicio la protección de los territorios. La realidad es que generan más pobreza, exclusión social, corrupción y migración al despojar a las personas de sus territorios que al también ver la perdida de sus tierras migraran a otros lugares del país o fuera de Honduras, en busca de otras alternativas. 


\section{BIBLIOGRAFÍA}

- Martínez Castillo, Mario Felipe, (2011) Los forjadores de nuestra identidad, primera edición, Tegucigalpa, Litografía López.

- Instituto Nacional de Estadísticas, 22 julio de 2021, Censos de población recuperado en 19 de agosto 2021de: https://www.ine.gob.hn/ V3/

- Cáceres Lara, Víctor, (1978) Gobernantes de Honduras en el siglo XIX, Editorial diseños offset, Banco central de Honduras.

- Presencia Universitaria, 21 febrero 2010, Propuesta académica de Carta Magna sería abierta y moderna recuperado en 19 de agosto 2021 de https://presencia.unah.edu. hn/noticias/propuesta-de-carta-magna-de-launah-seria-abierta-y-moderna/

- Orellana, X. CESPAD, 23 junio 2021, Las verdades a medias detrás de la promoción de las ZEDEs, recuperado e 19 de agosto 2021 de https://cespad.org.hn/2021/06/23/lasverdades-a-medias-detras-de-la-promocionde-las-zedes/

- Consejo de Secretarios de Estado, 22 octubre 2020, Honduras se convertirá en el polo de desarrollo de la región con las ZEDE recuperado en 20 de agosto de 2021 de http://www.consejosecretariosdeestado.gob. hn/content/honduras-se-convertir\%C3\%A1en-el-polo-de-desarrollo-de-la-regi\%C3\%B3n$\underline{\text { con-las-zede }}$
- López, B. CESPAD, 2 de agosto 2021, Análisis | Honduras: la lucha ciudadana contra las ZEDEs, recuperado en 20 de agosto 2021 de http://cespad.org.hn/2021/08/02/ analisis-honduras-la-lucha-ciudadana-contralas-zedes/

- Salazar M. Mongabay,10 febrero 2017, Honduras: ¿Qué revela nuevo informe sobre asesinatos de ambientalistas? https:// es.mongabay.com/2017/02/honduras-revelanuevo-informe-asesinatos-ambientalistas/

- OACNUDH, 2021, Acerca de los defensores de los derechos humanos recuperado en 20 de agosto 2021 de https://www.ohchr.org/ SP/Issues/SRHRDefenders/Pages/Defender. $\underline{\text { aspx }}$

- Reyes, C. International Land Coalition, Situación de defensoras y defensores de la tierra y el medio ambiente recuperado en 20 de agosto 2021 en https://d3o3cb4w253x5q. cloudfront.net/media/documents/Informehonduras-LandCoalition-V2 1.pdf

- La Prensa, 8 julio 2021, Zede Prospera quiere tener 10,000 habitantes para 2025, recuperado el 21 de agosto de 2021 en https://www. laprensa.hn/honduras/1476684-410/zedeprospera-quiere-tener-10000-habitantes-para2025-honduras

- La Prensa, 27 de junio 2021, Prospera tratara a los hondureños como extranjeros al exigir una residencia por $\$ 260$ dólares, recuperado el 21 de agosto de 2021 en https://www.laprensa. hn/premium/1473951-410/prospera-tratarahondure $\% \mathrm{C} 3 \% \mathrm{~B} 1$ os-como-extranjeros-exigirresidencia-zede 
- Palma-Herrera José Luis,05 de agosto de 2019, El regreso de los enclaves a Honduras en el siglo XXI: Las zonas de empleo y desarrollo económico (ZEDE), la versión de las ciudades chárter rechazada por su creador Paul Romer (2010-2019), Anuario de estudios centroamericanos, Universidad de Costa Rica, Volumen 45, recuperdo en 21 de agosto de 2019 de https://revistas.ucr.ac.cr/index. php/anuario/article/view/40696/41880

- DW, 18 de marzo 2021, Honduras: ¿soberanía a cambio de desarrollo económico? Recuperado en 22 de agosto de 2021 de https://www.dw.com/es/hondurassoberan \% C3\%ADa-a-cambio-de-desarrolloecon\%C3\%B3mico/a-56916122

- Criterio HN, 25 junio 2021, Inversionistas vendrán a Honduras en julio a explorar territorios para instalar nueva ZEDE Mariposa recuperado 22 de agosto de 2021 en https://criterio.hn/inversionistas-vendran-a$\underline{\text { honduras-en-julio-a-explorar-territorios-para- }}$ instalar-nueva-zede-mariposa/ 